three-phase, four-wire alternating current system of supply is being taken as the standard, the pressure of supply from the three outers to the neutral main being 230 volts. There is still a large number of supply stations in Great Britain which do not use the standard system, and if they are to reap the benefits of standardisation they must change to a.c. In a paper by H. Blades and A. C. MacQueen, read to the Institution of Electrical Engineers on March 31, this change-over is discussed. They show that the problems arising in dealing with small towns and suburban and residential districts are different from those arising in industrial and city areas. In the former areas the change-over from d.c. systems to a.c. systems should take place at the earliest possible opportunity. As the life of a.c. low pressure cables is, as a rule, about twice as long as that of d.c. cables, the costs for renewals would be considerably diminished. Some eight years ago a supply undertaking replaced a large section of its direct current network with very satisfactory results. The total cost of the change-over was cheaper than the estimated cost of replacing the old d.c. system and the maintenance and development charges were appreciably reduced. The faults which frequently occurred in the mains when direct current was used now practically never occur. The best methods of carrying out the change-over are given in the paper, and the necessary arrangements that have to be made with the consumers explained. As the number of consumers who have radio receivers actuated from the mains is rapidly increasing, the change-over costs to the supply companies increases concurrently, and this in addition to the engineering and technical reasons makes an early change from d.c. to a.c. advisable. In industrial and city areas the best rate at which the change-over should occur depends on the demand and the condition of the direct current plant.

\section{Clocks Worked from the Electric Supply Mains}

WHEN a house is supplied with alternating current electricity on the time-controlled system, it is possible to use an electric clock which keeps almost exact Greenwich time, the error being at the most only a few seconds per week. The principle used in their working is that of the synchronous motor, which keeps in exact step with the frequency of the alternating current, and the frequency is controlled by a ' master controller' regulated by Greenwich time so as to make it easy to synchronise the generators connected with the network. The clocks cost from thirty shillings upwards, depending on the size and design of the case used. The first synchronous clocks were used in the United States about twelve years ago, and, from their inventor, were called Warren clocks. In America more than six million have been sold and in Great Britain about a quarter of a million (Electrical Industries, March 16). They are made of two types. In one class the clock is self-starting and in the other it has to be started if the current stops even for a fraction of a second. In the latter class a red disc usually appears on the rare occasions when it stops. The clocks require only about half the power taken by an ordinary electric meter, and so the cost of running them is only a few pence a year. In America the sales are usually made by the electric supply companies, but in Great Britain the dealers who sell electric accessories and the clockmakers have taken up their sale. As a rule, the clocks require no attention for many months. In districts supplied by suitable alternating current, it is probable that this type of clock will supersede the escapement and pendulum type. Electric movements can be obtained to replace the ordinary clockwork movement of an existing clock.

\section{The Akron, the Airship of the United States Navy}

IN the new airship Akron built for the United States Navy there are incorporated several improvements which set new standards of efficiency for subsequent lighter-than-air machines. The ship is larger than most ocean liners and, unlike most of its predecessors, it is largely actuated by electricity and electrical apparatus. Particulars of the ship are given in the Westinghouse International for the first quarter of 1932. The power plant consists of two petrol-driven 11kilowatt generators, with a motor generator set for battery charging. The total weight allowed for the electrical system on board was only $3000 \mathrm{lb}$. Aluminium alloys were largely used for the machines and cables, and all the circuits are controlled from the generator room. The radio system takes the heaviest load from the generators. The antenna system consists of two trailing antennæ and a fixed wire antenna. The latter is used for landing manœuvres and for auxiliary purposes. Fire risk is practically eliminated, the twelve supporting gasbags of the ship being filled with helium; but even if they had been filled with hydrogen there would have been little risk of explosion, as every power outlet on the ship is so constructed that the plug cannot be removed or inserted unless its switch is in the 'off' position. Miniature lightning arresters protect the ship from static charges of electricity picked up while the ship is in flight, especially when she changes from one equipotential surface of the earth's electric field to the other. These arresters also drain off any electrostatic charges that might be induced by the ship's radio. The telephone system has seventeen telephones, the switchboard on which the keys and lamps are mounted weighing only thirty pounds. A special feature of the Akron is the powerful searchlight which is used for signalling and for landing. It consists of a 500-watt lamp with a fourteen-inch reflector. In daylight tests its light is brilliantly visible at a distance of four miles.

\section{Recent Acquisitions at the Natural History Museum}

The Zoological Department of the Museum has secured a mounted example of an exceedingly rare marsupial mouse, Conolestes obscurus, from Mount Pichincha, Quito, Ecuador. This species belongs to that group of marsupials which, from the possession of only two incisor teeth in the lower jaw, is known as the Diprotodontia. Except for this solitary species, found in a restricted area of the high Alpine country of the Central Andes in Venezuela, Colombia, Ecuador, and Peru, the diprodont marsupials are found only in the Australian region. The Department of

No. 3261, VoL. 129] 